6.

Derecho administrativo 

Revista de Derecho

de la Pontificia Universidad Católica de Valparaíso

XXXIV (Valparaíso, Chile, ${ }^{\text {er }}$ Semestre de 2010)

[pp. 545- 568]

\section{RÉGIMEN JURÍDICO DEL INTERCAMBIO DE ANIMALES Y SUS \\ PRODUCTOS EN LA UNIÓN EUROPEA Y EN ESPAÑA}

["Legal System Regarding Trade of Animals and their Products in the

European Union and Spain”]

ISABEL GONZÁLEZ Ríos*

Universidad de Málaga, España

\section{RESUMEN}

La sanidad y la protección de animales constituyen un sector de la política agrícola comunitaria que ha sido objeto de una importante regulación normativa. Y ello es así desde que diversas enfermedades en animales de producción (v.g. encefalopatía espongiforme transmisible, la gripe aviar...) crearan una importante alarma social por los posibles riesgos que entrañaban para la seguridad alimentaria de los consumidores de productos de origen animal. Muchas y variadas son las medidas de sanidad y de protección animal que recoge la normativa comunitaria y que han tenido su correspondiente reflejo en la regulación interna de los Estados miembros, pero en este trabajo hemos querido centrarnos en el análisis del comercio intracomunitario y con terceros países de animales, por el

\begin{abstract}
Animal health and protection is an area of the common agricultural policy that has been subject to significant legal regulation. This has been so since different diseases in production animals (that is, transmissible spongiform encephalopathy, avian influenza...) triggered an important social alarm due to the possible risks involved in food security of consumers of products of animal origin. Albeit the Community rules contain many different health and animal protection measures that have been captured in the internal regulation of the Member States, this work aims to the intra-Community trade of animals with third countries due to the significant risk that the propagation of epizootic and zoonosis entails for the herds and for human health. In this regard, we will
\end{abstract}

* Profesora titular de Derecho administrativo de la Facultad de Derecho de la Universidad de Málaga, España. Dirección postal: Universidad de Málaga, Facultad de Derecho, Campus de Teatinos S/N ( CP.29701) Málaga, España; Correo electrónico: isa_gonzalez@uma.es 
considerable riesgo que para la cabaña ganadera y para la salud humana conlleva la propagación de epizootias y zoonosis. $\mathrm{Al}$ respecto, abordaremos las medidas sanitarias aplicables al intercambio intracomunitario y con terceros países de animales y sus productos, así como las técnicas de protección de animales durante su transporte.

Palabras clave: Sanidad animal Protección de animales - Exportación e importación de animales. address the sanitary measures applicable to the intra-Community trade of animals and their products with third countries, as well as the animal protection techniques while they are in transit.

KeYwords: Animal health - Animal protection - Animal export and import.

\section{LA INTERVENCIÓN DE LA UNIÓN EUROPEA} RESPECTO AL MOVIMIENTO DE ANIMALES Y SUS PRODUCTOS

El control del movimiento y transporte de animales por el territorio nacional y fuera de nuestras fronteras tiene por objeto garantizar la no propagación de epizootias y zoonosis, así como la protección de los animales durante el transporte ${ }^{1}$.

La desaparición de las fronteras a nivel comunitario para contribuir al desarrollo de un mercado interior agrario, la mejora en los medios de comunicación, la proximidad con Portugal y Francia y el hecho de que Ceuta y Melilla se encuentren en contacto directo con los países del Magreb, facilita la transmisión de enfermedades animales al territorio nacional y comunitario.

Se hace necesaria, pues, la regulación de las condiciones sanitarias y de bienestar animal que deben cumplirse en el movimiento de animales y de sus productos para evitar la propagación de aquellas enfermedades. Pero

\footnotetext{
${ }^{1} \mathrm{Al}$ respecto: Adrián ArnaIz, A. J., Globalización y seguridad alimentaria en la Unión Europea, en Revista de Estudios Europeos, 25 (2000); BuXade CARbO, C., El desafio: ganadería española. CEE de los Doce (Madrid, Ediciones Mundi Prensa, 1988); GonZÁlez Ríos, Isabel, Sanidad animal y seguridad alimentaria en los productos de origen animal (Granada, Comares, 2004), pp. 221 ss.; LA MISMA, Las explotaciones ganaderas ante la Sanidad Animal. Controles sanitarios, derechos y deberes de los titulares de las mismas, en Revista de Justicia Administrativa, 41 (2008), pp. 5 ss.; MuÑOZ Machado, Santiago, Los animales y el Derecho (Madrid, Civitas, 1999); QuinTana López, Tomás, Derecho veterinario: epizootias y sanidad animal (Madrid, Marcial Pons, 1993), pp. 145 ss.; Rebollo Puig, Manuel, Potestad sancionadora, alimentación y salud pública (Madrid, Ministerio de Administraciones Públicas, 1989).
} 
para que dicha regulación sea efectiva se requiere de la armonización de las legislaciones de los Estados miembros de la Unión Europea (UE).

En este sentido, corresponde a las Instituciones Comunitarias la regulación de todos los aspectos relativos al intercambio intracomunitario y con terceros países de animales y sus productos y del régimen de protección animal durante su transporte.

Tres políticas comunitarias amparan la intervención de la $\mathrm{UE}^{2}$ en materia de movimiento de animales. En primer lugar, "la libre circulación de mercancías", que pretende crear un mercado interior de productos comunitarios sin barreras aduaneras, lo que no impide que se puedan establecer "prohibiciones o restricciones a la importación, exportación o tránsito" justificadas en la protección de la salud y vida de las personas y animales ${ }^{3}$.

En segundo lugar, la política agraria y comercial común justifica la intervención de la UE en la materia ${ }^{4}$. Esta última implica la desaparición de las fronteras intracomunitarias y el reforzamiento de las exteriores, lo que fundamenta la diferente regulación aplicable a los intercambios de animales y sus productos según sean intracomunitarios o con terceros países.

Junto a estas tres políticas comunitarias, la protección de la salud pública $^{5}$, de los consumidores ${ }^{6}$ y del medio ambiente, también avalan la

${ }^{2}$ Artículos 23 ss del Tratado Constitutivo de la Comunidad Europea, de 25 de marzo de 1957 (= TCCE), modificado por el Tratado de la Unión Europea, de 7 de febrero de 1992, por el "Tratado de Ámsterdam", de 2 de octubre de 1997 y por el "Tratado de Niza", de 26 de febrero de 2001.

${ }^{3}$ Artículo 30 TCCE. Este tipo de prohibiciones ha sido interpretado de forma restrictiva por el Tribunal de Justicia de la Comunidad Europea en su sentencia de 13 de julio de 1994, al considerar que no caben prohibiciones a la importación por motivos de sanidad animal si resultan desproporcionadas al objetivo que se trata de conseguir. Así si el objetivo a conseguir se puede lograr con medidas menos restrictivas que la prohibición de intercambios, se deben adoptar las mismas.

${ }^{4}$ Argullol Murgadas, E., Competencias de la Comunidad Europea y de las Comunidades Autónomas en materia de política agraria, en La integración de España en las Comunidades Europeas y las competencias de las Comunidades Autónomas (Barcelona, Generalitat de Cataluña, 1985); Castillo Gamero, N. - Hernández la Fuente, A., La política agraria, en Tratado de Derecho Comunitario Europeo (Madrid, Cívitas, 1986), III.

${ }^{5}$ Martín González, Salud pública. Concepto y encuadramiento (Madrid, 1970), III; Martín Mateo, Ramón, Ordenación pública del sector salud, en Revista de Administración Pública, 84 (1997); Yuste Grijalva, J. F., Salud pública y desarrollo, en Documentación Administrativa, 114 (1967).

${ }^{6}$ Entre otros: SÁnchez BlAnCO, Ángel, El consumidor ante la política de abastecimiento y ante la política comercial, en Revista de Administración Pública, 85( 1978); ValenZuela García, F., La intervención administrativa en materia de alimentación, en Documentación Administrativa, 194 (1982). 
intervención de la UE en sanidad y bienestar animal ${ }^{7}$. No olvidemos que el peligro que para la salud humana entraña las zoonosis o enfermedades animales transmisibles al hombre ha intensificado la regulación de la UE $\mathrm{y}$ viene, desde haces algunas décadas, originando una importante alarma social a raíz de enfermedades animales como la Encefalopatía Espongiforme Bovina o la gripe aviar ${ }^{8}$.

Teniendo en cuenta esa habilitación competencial comunitaria que se desprende del Derecho Originario europeo, las Instituciones comunitarias vienen aprobando un importante número de Directivas y Decisiones en materia de intercambios intracomunitarios y con terceros países y sobre el transporte de animales, que se ha asumido como derecho interno, principalmente a través de normas de rango reglamentario de naturaleza básica. Las competencias estatales en materia de sanidad animal ${ }^{9}$ justifican dicha regulación reglamentaria. Esta regulación no ha impedido la aprobación de dos leyes estatales básicas, la Ley de Sanidad Animal ${ }^{10}$ y la Ley para el cuidado de los animales, en su explotación, transporte, experimentación y sacrificio ${ }^{11}$, que regulan determinados aspectos del movimiento de animales.

Por otra parte, si bien tanto las CC. AA [= "comunidades autónomas"] como los Entes Locales ostentan competencias en materia de sanidad animal a través de distintos títulos competenciales, entre los que destaca la competencia autonómica en materia de "agricultura y ganadería, de acuerdo con la ordenación general de la economía" (art. 148.1 7 CE) $)^{12}$, su regulación en materia de movimiento de animales se centra en el rea-

${ }^{7}$ Artículos 152, 153 y 174 ss TCCE.

${ }^{8}$ Callejo Javier, La crisis de la Encefalopatía Espongiforme: Huecos en el modelo social de consumo, en la Revista de Estudios sobre Consumo, 58 (2001); CARTAGENA PASTOR, F., Protección alimentaria del consumidor. Aspectos legales y aplicaciones prácticas de investigación y enjuiciamiento de los delitos contra la salud pública derivados del tratamiento ilegal de animales destinados al consumo humano. Consideraciones generales, en Revista de Estudios sobre Consumo, 58 (2001); GonZÁlez Botija, F., La crisis de las vacas locas y los límites de las protecciones de la salud pública en el mercado interior, en Revista de Estudios Europeos, 17 (1997).

${ }^{9}$ GonzÁlez Ríos, Isabel, Sanidad Animal y Seguridad Alimentaría, cit (n. 1), pp. 19 ss.

${ }^{10}$ Ley No 8/03, de 24 de abril, de Sanidad animal.

${ }^{11}$ Ley No 32/07, de 7 de noviembre, Para el cuidado de los animales, en su explotación, transporte, experimentación y sacrificio.

${ }^{12}$ Navarro Caro, J., Cuestiones de constitucionalidad relativas al reparto competencial entre el Estado y las Comunidades Autónomas en Derecho Agrario Español, en Diputación Provincial de Aragón (editora), Derecho Agrario Español y de todas las Comunidades Autónomas (Zaragoza, 1993), p. 262. 
lizado dentro de su ámbito territorial, por lo que no pueden incidir en la regulación del comercio intracomunitario y con terceros países.

\section{MEDIDAS SANITARIAS PARA EL CONTROL DEL MOVIMIENTO}

DE ANIMALES Y SUS PRODUCTOS

\section{Movimiento dentro del territorio español.}

La Ley de Sanidad Animal (LSA.) española ha regulado en el título $3^{\circ}$ ("organización sanitaria sectorial"), en su capítulo $4^{\circ}$ la "ordenación sanitaria del mercado de los animales". Dentro de este Capítulo, la Sección $1^{\text {a }}$ se dedica al comercio, transporte y movimiento pecuario dentro del territorio nacional, mientras que el transporte o comercio fuera del territorio nacional aparece regulado dentro del título $2^{\circ}$, capítulo $12^{\circ}$, referido a "los intercambios con terceros países".

La regulación que realiza la LSA. sobre el movimiento pecuario dentro del territorio nacional ha sido desarrollada en parte por el Real Decreto $\mathrm{N}^{\circ} 728 / 07$, de 13 de junio, por el que se establece y regula el Registro general de movimientos de ganado y el Registro general de identificación individual de animales.

Por lo que respecta a las medidas sanitarias aplicables al comercio, transporte y movimiento pecuario dentro del territorio nacional, la LSA. ${ }^{13}$ exige un "certificado sanitario de origen" 14 emitido por un veterinario ${ }^{15}$, que tradicionalmente se ha denominado "guía de origen y sanidad pecuaria”, pudiendo exigirse certificados especiales cuando se trate de animales

${ }^{13}$ Ello en base a los títulos de competencia del Estado sobre "sanidad exterior", "bases y coordinación general de la sanidad", "comercio exterior" o "igualdad de todos los españoles en el ejercicio de derechos y deberes constitucionales" (artículo 149.1.1, 10, 16 CE).

${ }^{14} \mathrm{El}$ Tribunal Supremo ha fijado doctrina legal sobre el objeto y finalidad de dichos certificados, tradicionalmente denominados "Guía de origen y sanidad pecuaria” en la sentencia de 30 de octubre de 2001 (ponente Antonio Martí García), estableciendo que los mismos acreditan exclusivamente que los animales proceden de una zona no infectada y que no padecen enfermedad infecto, contagiosa o parasitaria difusible y, en consecuencia, su otorgamiento no impide que la Administración competente realice controles o servicios veterinarios en los mataderos destinados a la detección de posibles sustancias perjudiciales para la salud humana en los animales sacrificados. En esta sentencia el Tribunal Supremo casa una sentencia que estimó un recurso contencioso administrativo interpuesto contra una sanción impuesta a un ganadero tras detectar en el matadero que a unos terneros se les había suministrado "Clembuterol". En la sentencia de instancia se estimaba que el otorgamiento de la "Guía de origen y sanidad pecuaria" habilitaba para el traslado de los animales y certificaba que las reses eran aptas para el consumo.

${ }^{15}$ Artículo 50 LSA. 
sometidos a restricciones específicas o productos de riesgo o en situación de emergencia sanitaria. También se exige certificado sanitario oficial para la trashumancia del ganado.

Estos certificados sanitarios de origen podrán servir de documento de movimiento siempre que contengan unos datos mínimos establecidos en el Reglamento que regula el Registro general de movimiento de ganado, tales como los datos de la explotación de origen, los de la explotación de destino, los relativos al movimiento de animales o la conformidad del titular de la explotación de origen ${ }^{16}$.

Si dichos certificados sanitarios no reúnen esos datos se deberá disponer del documento de movimiento de ganado debidamente cumplimentado por el titular o poseedor de los animales o por la autoridad competente ${ }^{17}$. No obstante, los movimientos de animales dentro de una misma CC. AA. podrán ser excepcionados del documento de movimiento, siempre que pueda ser sustituido por un sistema que presente las mismas garantías ${ }^{18}$.

Dichos certificados sanitarios de origen deben acompañarse con una autorización otorgada por la CC.AA. respecto a los medios de transporte de animales y la empresa propietaria ${ }^{19}$. Además, los medios de transporte, una vez descargados los animales, deben ser limpiados y desinfectados en el centro de limpieza y desinfección más cercano ${ }^{20}$, que deberá expedir un justificante que acompañara al transporte ${ }^{21}$.

Cuando el movimiento de animales se realice entre CC.AA., la CC.AA. de origen deberá comunicarlo a la de destino, y cuando se transporte animales o productos considerados de riesgo se deberá comunicar también a las CC.AA. de tránsito ${ }^{22}$.

El titular de cada explotación o el poseedor de los animales deberá comunicar a la autoridad competente de la CC.AA. los movimientos de ganado que se produzcan en su explotación. La explotación de origen comunicará la salida de los animales y la de destino su entrada a la CC.AA. en que radiquen sus explotaciones. Esta comunicación se debe realizar en el plazo máximo de 7 días desde que tenga lugar el movimiento, sin perjuicio

${ }^{16}$ Artículo 6.2 y Anexo VII del Real Decreto No 728/07, de 13 de junio, por el que se establece y regula el Registro general de movimientos de ganado y el Registro general de identificación individual de animales.

${ }^{17}$ Artículo 6.1 del Real Decreto No 728/07, de 13 de junio.

${ }^{18}$ Artículo 6.4 del Real Decreto No 728/07, de 13 de junio.

${ }^{19}$ Artículo 47 LSA.

${ }^{20}$ Hemos de tener en cuenta que recientemente se han regulado las condiciones básicas que deben cumplir los centros de limpieza y desinfección de los vehículos dedicados al transporte de ganado por carretera mediante RD 644/02, de 5 de julio

${ }^{21}$ Artículo 49 LSA.

${ }^{22}$ Artículo 51 LSA. 
de que disposiciones específicas puedan establecer un plazo inferior ${ }^{23}$.

La comunicación a las CC.AA. se realizará mediante una copia del documento de movimiento o por cualquier medio informático o telemático establecido por la autoridad competente ${ }^{24}$.

A fin de garantizar un adecuado control del movimiento pecuario, además de las medidas antes citadas la LSA. prevé la creación de un Registro Nacional de carácter informativo que recogerá los susodichos movimien$\operatorname{tos}^{25}$. Así se ha creado en 2007 el Registro de Movimiento de Animales $(\mathrm{REMO})^{26}$, adscrito en un principio a la Dirección General de Ganadería del Ministerio de Agricultura, Pesca y Alimentación, y actualmente a la Dirección General de Recursos Agrícolas y Ganaderos del Ministerio de Medio Ambiente y del Medio Rural y Marino, que asume sus funciones ${ }^{27}$. En el mismo figurarán los datos obrantes en los registros de las CC. AA., que deben estar informatizados y permitir que los movimientos de animales en ellos registrados tenga reflejo inmediato en el $\mathrm{REMO}^{28}$.

Esta regulación estatal básica hemos de complementarla con la legislación que algunas CC. AA. han dictado en materia de sanidad pecuaria, que en ningún caso puede contradecir aquella regulación ${ }^{29}$.

\section{Movimiento intracomunitario y con terceros paises.}

La UE viene aprobando abundante normativa referida al comercio intracomunitario y con terceros países de animales y sus productos ${ }^{30}$. Di-

${ }^{23}$ Artículo 5.1 del Real Decreto No 728/07, de 13 de junio, por el que se establece y regula el Registro general de movimientos de ganado y el Registro general de identificación individual de animales. Dicha comunicación debe contener los datos que figuran en el Anexo VI de dicho Reglamento (datos de la explotación, datos de la explotación de destino, datos del movimiento de animales).

${ }^{24}$ Artículo 5.3 del Real Decreto No 728/07, de 13 de junio.

${ }^{25}$ Artículo 53 LSA.

${ }^{26}$ Real Decreto No 728/07, de 13 de junio.

${ }^{27}$ Real Decreto No $1130 / 08$, de 4 de julio, por el que se regula la estructura orgánica básica del Ministerio de Medio Ambiente y del Medio Rural y Marino.

${ }^{28}$ Artículo 3 del Real Decreto No 728/07, de 13 de junio.

${ }^{29}$ La Ley de sanidad animal de Castilla y León, de la Comunidad Foral Navarra y de La Rioja regulan el tipo de documentación a exigir para el traslado o movimiento de animales. En Andalucía es el Real Decreto No 55/98, de 10 marzo, el que regula el movimiento y transporte de ganado y otros animales vivos.

${ }^{30} \mathrm{~A}$ las directivas y decisiones del Consejo y de la Comisión de la Unión Europea sobre intercambios intracomunitarios e importación de ganado y sus productos, las cuales vienen siendo traspuestas al Derecho interno vía reglamento, se une el artículo 30 TCCE que permite a los Estados miembros adoptar las prohibiciones o restricciones a la importación, exportación o tránsito, justificadas por razones de protección de la salud y vida de las personas y animales, entre otras. 
cha normativa recogida en Directivas comunitarias ha sido traspuesta al Derecho interno por diversos reglamentos estatales básicos ${ }^{31}$, aprobados con anterioridad a la LSA. Sin embargo, la LSA. se refiere exclusivamente a los intercambios con terceros países, sin contener previsión alguna de carácter básico sobre el comercio intracomunitario de animales y sus productos.

Así pues, el legislador ha considerado necesario contener previsiones de carácter básico con rango legal respecto de los intercambios de animales y sus productos con terceros países, y sólo de rango reglamentario para los intercambios intracomunitarios.

No obstante, en la medida en que los Reglamentos estatales básicos, anteriores en el tiempo a la LSA., son transposición de normativa comunitaria, la regulación contenida en los mismos debía ser respetada en aquella Ley. La regulación contenida en dichos reglamentos tiene prevalencia, al ser derecho comunitario, sobre la normativa interna. Por eso no se entiende que la LSA. no haya establecido ninguna previsión básica en cuanto el intercambio intracomunitario del ganado.

$\mathrm{Al}$ respecto de esta normativa analizaremos, en primer lugar, la regulación que realiza la LSA. y en segundo lugar, la normativa de trasposición del Derecho comunitario en materia de intercambios intracomunitarios y con terceros países de animales y sus productos.

Los intercambios con terceros países de animales, productos zoosanitarios o para la alimentación animal han sido regulados en la LSA. La misma contiene una regulación de competencia plena (artículos 149.1.16, 149.1.10 CE), que se centra en la necesaria inspección en frontera, en instalaciones adecuadas, de las importaciones y exportaciones ${ }^{32}$. Realizada la correspondiente inspección se adoptarán las medidas oportunas cuando se considere que la importación entraña algún riesgo sanitario grave, en caso contrario, se expedirá un certificado oficial veterinario que acompañará a la mercancía en los desplazamientos internos y que sustituye al certificado sanitario oficial establecido para el movimiento interno ${ }^{33}$. Para

${ }^{31}$ Dicha pluralidad normativa obedece a la regulación de determinados aspectos relacionados con dichos intercambios (v. gr. controles veterinarios); así como, y rompiendo con el carácter unitario que la materia tiene en el Reglamento de Epizootias de 4 de febrero de 1955, la regulación por separado de los intercambios intracomunitarios y con terceros países de distintas especies animales (v. gr. ganado bovino y porcino; aves de corral o ganado ovino y caprino) Así, pues, la regulación estatal sobre las condiciones sanitarias aplicables en la importación y exportación del ganado se realiza agrupando en un mismo reglamento las determinaciones relativas a una o dos especies animales, tanto en lo relativo a los intercambios realizados dentro de la UE como si se trata de importaciones procedentes de terceros países.

${ }^{32}$ Artículo 12 LSA.

${ }^{33}$ Artículo 13 LSA. 
la exportación también se requiere el correspondiente certificado sanitario emitido en frontera, la exportación sin previa obtención del mismo será responsabilidad del exportador ${ }^{34}$.

Mención especial en materia de intercambios (importaciones y exportaciones) requieren los que se realicen desde o hacia Ceuta y Melilla. Así, la importación y exportación de animales, productos zoosanitarios o para la alimentación animal se realizará a través de los puestos de inspección fronterizos [= PIF] o centros de inspección autorizados ${ }^{35}$.

Esta medida hace que incluso cuando se trate de importar o exportar animales o los citados productos a Estados miembros de la UE, aún tratándose de intercambios intracomunitarios se va a exigir la inspección en los correspondientes PIF o puestos autorizados, no bastando con el control en origen y en destino.

Pero es más, también la entrada de animales, productos de origen animal, productos zoosanitarios y productos para la alimentación animal, en el resto del territorio nacional debe realizarse a través de los PIF o centros de inspección autorizados o puntos de entrada autorizados por la Administración General del Estado ${ }^{36}$.

El hecho de que el comercio con dichas ciudades autónomas se someta a esa inspección en frontera, a pesar de tratarse de comercio realizado dentro del territorio nacional, obedece a su situación geográfica, a su proximidad a los países del Magreb, fuente de importantes contagios epizoóticos.

Por lo que respecta a la normativa de transposición del Derecho Comunitario, la misma distingue según la especie animal y el tipo de producto al que se refiera el intercambio, como a continuación analizamos.

a) Intercambios intracomunitarios e importaciones de terceros países de las especies ovina y caprina. La UE reguló esta materia en la Directiva No 91/68/CEE, del Consejo, de 28 de enero, relativa a las normas de policía sanitaria que regulan los intercambios intracomunitarios de animales de las especies ovina y caprina ${ }^{37}$, así como en la Directiva No 91/69/CEE, del Consejo, de 28 de enero, que modifica a la Directiva No 72/462/CEE relativa a problemas sanitarios y de policía sanitaria en las importaciones de animales de las especies bovina y porcina, de carnes

${ }^{34}$ Artículo 14 LSA.

${ }^{35}$ DA $2^{\mathrm{a}}, 1^{\mathrm{a}}$ LSA.

${ }^{36}$ DA $2^{\circ} .2$ LSA.

${ }^{37}$ Esta Directiva ha sido modificada por la Directiva No 2001/10/CE, del Parlamento Europeo y del Consejo, de 22 de mayo y por la Directiva No 2003/50/CE, del Consejo, de 11 de junio, intensificando los controles sobre el movimiento de ovinos y caprinos. 
frescas y de productos a base de carne procedentes de terceros países, con la finalidad de incluir a los animales de la especie ovina y caprina.

Así, la pertenencia de España a la UE supone la existencia de unas normas comunes de comercialización intracomunitaria de ovinos y caprinos y de un régimen jurídico aplicable a las importaciones de estos animales procedentes de terceros países con el objeto de evitar la propagación de epizootias y proteger la cabaña ganadera comunitaria.

Dichas Directivas fueron objeto de trasposición por el Reglamento de 3 de diciembre de $1993^{38}$, el cual ha sido derogado para adaptarse a la normativa comunitaria por el Reglamento de 27 de septiembre de $2004^{39}$. La regulación contenida en el mismo abarca a los intercambios intracomunitarios y a las importaciones de terceros países.

Los intercambios in traco munitario ${ }^{40}$ de las citadas especies ovina y caprina se someten a una serie de requisitos. Entre aquellos requisitos figuran los que tienen una naturaleza de control previo, los de carácter especial referidos a los animales de abasto, reproducción y engorde y las condiciones impuestas para el movimiento de estas especies animales.

Entre los requisitos de carácter preventivo se encuentran el estar identificados y registrados, el sometimiento a un examen veterinario 24 horas antes de su carga y no mostrar signo clínico de enfermedad, no proceder ni haber estado en contacto con animales de una explotación sujeta a prohibición por motivos sanitarios, la exclusión del intercambio de los animales que deban ser sacrificados, haber nacido y haberse criado en el territorio de la UE o haber sido importados de un tercer país según los requisitos fijados en este Reglamento, etc.

Entre las condiciones que se imponen al movimiento de animales ovinos y caprinos figuran: el que los animales no estén fuera de su explotación de origen más de 6 días después de haber sido certificados por última vez para el comercio a su destino final de un país miembro, aunque en caso de transporte marítimo el plazo se prorroga por el tiempo que dure la travesía; tras salir de la explotación los animales se enviarán directamente

${ }^{38}$ Real Decreto No 2121/93, de 3 de diciembre, relativo a las normas de policía sanitaria que regulan los intercambios intracomunitarios y las importaciones de terceros países de animales de las especies ovina y caprina, el cual ha sido recientemente modificado el Real Decreto No 903/2001, de 27 de julio, a fin de adaptar la regulación a la última de las Directivas comunitarias en la materia.

${ }^{39}$ Real Decreto No 1941/04, de 27 de septiembre, por el que se establecen las normas de policía sanitaria que regulan los intercambios intracomunitarios y las importaciones de terceros países de animales de la especie ovina y caprina; modificado por Real Decreto 1085/05, de 16 de septiembre.

${ }^{40}$ Artículos 3 ss del Real Decreto No 1941/04, de 27 de septiembre. 
al destino de otro Estado miembro; los animales de abasto que se hayan destinado a matadero en el país de origen deberán ser sacrificados lo antes posible, a más tardar 72 horas después de su llegada.

Además, durante su transporte los animales deberán ir acompañados de un certificado sanitario, que se expedirá el día del examen veterinario y debe ir en castellano y en uno de los idiomas oficiales del país de destino. Este certificado tendrá una validez de 10 días. Dicho veterinario oficial velará porque se registre el movimiento de animales en el sistema ANIMO el día en que se expide el certificado ${ }^{41}$.

La regulación referida al intercambio de estas especies animales con terceros países que contenía el Reglamento que comentamos ha sido derogada por el Reglamento de 16 de septiembre de 2005, que establece las normas zoosanitarias para la importación y tránsito por España de determinados ungulados vivos procedentes de terceros países ${ }^{42}$. La actual normativa establece un listado de países autorizados desde los que se permite la importación de ungulados y recoge las garantías que debe ofrecer el país tercero, tales como que los animales deben reunir las condiciones sanitarias específicas que establezca la Comisión Europea, que se debe realizar un control veterinario previo a su salida e ir acompañado de un certificado veterinario, que al llegar a España se debe realizar un control en el Puesto de Inspección Fronteriza. No obstante, se admiten excepciones a dichas garantías.

Hemos de tener en cuenta que la LSA. sólo exige el certificado sanitario expedido en el correspondiente PIF ${ }^{43}$. Ello no impide que reglamentariamente se exija dicho certificado expedido por veterinario oficial del país exportador, al ser un requisito impuesto por la normativa comunitaria en la materia, traspuesta mediante Reglamento de carácter básico. No obstante, hubiera sido oportuno que la LSA. hiciese alusión a dicho certificado, por cuanto el mismo es exigido en la normativa europea para la importación de cualquier especie animal procedente de terceros países, como analizaremos.

b) Intercambios intracomunitarios e importaciones de terceros países en materia de avicultura. La regulación en materia de avicultura va referida a los intercambios intracomunitarios e importaciones procedentes de terceros países relativas a aves de corral, huevos para incubar y carnes frescas de dicho tipo de aves.

i) Carnes frescas de aves de corral. El fundamento de la regulación

\footnotetext{
${ }^{41}$ Artículo 15 del Real Decreto No 1941/04, de 27 de septiembre.

${ }^{42}$ El artículo 2 del Real Decreto No 1085/05, de 16 de septiembre, define los países terceros como aquellos distintos de los países miembros de la UE.

${ }^{43}$ Artículo 13.3 LSA
} 
española en la materia relativa a carnes frescas de aves de corral se encuentra en la Directiva del Consejo No 91/494/CEE, de 26 de junio, sobre intercambios intracomunitarios y las importaciones de carnes frescas de aves de corral procedentes de terceros países, la cual fue modificada por la Directiva No 93/421/CEE, del Consejo, de 22 de diciembre y por la Directiva No 1999/89/CE, del Consejo de 15 de noviembre.

Estas Directivas han sido incorporadas al Derecho interno a través de sucesivos reglamentos por los que se asume su contenido ${ }^{44}$. Afortunadamente dicha materia ha sido objeto de refundición en el último de ellos, el Reglamento de 29 de junio de $2001^{45}$.

Este Reglamento contiene un concepto amplio de ave de corral en el que se incluyen entre otras especies: las gallinas, patos, codornices, faisanes, perdices, palomas, la producción de carne o huevos para el consumo, etc.

Por lo que respecta a los intercambios intracomunitarios de carnes frescas ${ }^{46}$ de dichas aves se requiere que cumplan una serie de requisitos referidos a la explotación de procedencia, que debe estar saneada, al transporte, al sacrificio y al marcado de inspección veterinaria ${ }^{47}$.

En cuanto a la importación de carnes frescas de aves de corral procedentes de terceros países, merece destacarse que sólo se considerarán terceros países o partes de los mismos los que así figuren en una lista elaborada por la Comisión de la Unión Europea.

Entre las condiciones que deben reunir las carnes frescas de aves de corral a importar figuran la necesidad de someterse a control por los servicios veterinarios oficiales de los puestos de inspección fronterizos, la obligación de ir acompañadas de un certificado expedido por un veterinario oficial del país tercero exportador y la posibilidad de que expertos veterinarios de la Comisión de la Unión Europea realicen inspecciones "in situ” para

${ }^{44}$ Real Decreto No 1322/92, de 30 de octubre, modificado por el Real Decreto No 362/95, de 10 de marzo y Real Decreto No 746/01, de 29 de junio.

${ }^{45}$ Real Decreto No 746/01, de 29 de junio, dictado al amparo de las competencias plenas del Estado en materia de comercio y sanidad exterior, y básicas sobre sanidad (artículo 149.1.10, 16 CE), modificado por Real Decreto No 1976/04, de 1 de octubre y por Real Decreto 640/06, de 26 de mayo.

${ }^{46}$ Toda carne que no haya sido sometida a ningún tratamiento distinto del frío para garantizar su conservación (artículo 2.d) del Real Decreto No 746/01, de 29 de junio.

${ }^{47}$ A esta marca se refiere el Real Decreto No 2087/94, de 20 de octubre, que regula las condiciones sanitarias de producción y comercialización de carnes frescas de aves de corral, cap. XII del Anexo I, que establece que la misma debe efectuarse bajo la supervisión del veterinario oficial. Dicho Reglamento se ha visto modificado por el Real Decreto No 1916/97, de 19 de diciembre y por el Real Decreto No 1977/99, de 23 de diciembre. 
verificar el cumplimiento de los requisitos impuestos por la normativa comunitaria en la materia.

ii) Aves de corral y huevos para incubar.Dada la importancia que la avicultura representa actualmente en la alimentación humana se requiere su sometimiento a constantes controles veterinarios. Dichos controles deben realizarse de forma armonizada en el seno de la Unión Europea para la consecución del Mercado Único, lo que ha hecho que la UE venga aprobando diversas normas que contienen las determinaciones de policía sanitaria aplicables a los intercambios intracomunitarios e importaciones de terceros países de aves de corral y huevos para incubar ${ }^{48}$.

Toda la normativa comunitaria sobre esta materia ha sido objeto de trasposición al Derecho interno por sucesivos reglamentos, encontrándose actualmente refundida en el Reglamento de 22 de noviembre de $2000^{49}$.

Dicho Reglamento contiene una detallada regulación de los intercambios intracomunitarios de aves de corral y huevos para incubar, en la que cabe destacar la necesaria procedencia de explotaciones saneadas, la obligación de someterse a un examen sanitario por un veterinario designado por los órganos competentes de las CC. AA. antes de su expedición, la posibilidad de obtener el reconocimiento como regiones indemnes de enfermedades aviares $^{50}$, las obligaciones relativas al etiquetado y transporte, así como, la obligación de que las aves de corral y huevos para incubar vayan acompañados de un certificado sanitario ${ }^{51}$.

${ }^{48}$ En este sentido, dicha materia se reguló en la Directiva No 90/539/CEE, del Consejo, de 15 de octubre, a la cual siguieron la Directiva No 93/120/CE, del Consejo y las Decisiones de la Comisión No 92/340, No 92/369, No 93/152 y No $94 / 327$, relativas a dos de las epizootias más frecuentes entre las aves como son la enfermedad de Newcastle y la influencia aviar. Sin embargo, la regulación contenida en la primera de dichas normas, la Directiva 90/539/CEE del Consejo, fue objeto de modificación por la Directiva No 1999/90/CE, del Consejo de 15 de noviembre, sobre todo, por la incorporación a las aves de corral de las aves del grupo de la Struthioniformes, representadas fundamentalmente por los avestruces.

${ }^{49}$ Real Decreto No 1888/00, de 22 de noviembre, sobre intercambios intracomunitarios e importaciones de terceros países de aves de corral y huevos para incubar. El Anexo III de este Reglamento ha sido modificado por la Orden APA/771/2003, de 26 de marzo.

${ }^{50}$ Para ello se requiere que la CC. AA que se considere total o parcialmente indemne de una enfermedad a la que estén expuestas las aves de corral presente las debidas justificaciones a la Dirección General de Ganadería del MAPA (actual Dirección General de Recursos Agrícolas y Ganaderos del Ministerio de Medio Ambiente y del Medio Rural y Marino), que las examinará y, en su caso, las presentará a la Comisión Europea para que sean reconocidas las garantías complementarias al comercio intracomunitario de aves de corral destinadas a ese territorio.

${ }^{51} \mathrm{Al}$ igual que se exige para la comercialización de las carnes frescas de estas aves. 
Además, para poder realizar intercambios intracomunitarios las granjas deberán estar debidamente autorizadas por los órganos competentes de las CC. AA..$^{52}$, para ello deberán reunir las condiciones de instalación y funcionamiento que regula el citado Reglamento, dicha autorización podrá suspenderse o retirarse en diferentes supuestos.

Por lo que respecta a las importaciones de terceros países de aves de corral y huevos para incubar, el Reglamento de 22 de diciembre de 2000 establece entre otras exigencias: la procedencia de países terceros o partes de los mismos que figuren en una lista elaborada por la Comisión Europea; el sometimiento a control por los servicios veterinarios designados por la Administración General del Estado adscritos a los puestos de inspección fronterizos autorizados a tal fin; el país tercero del que procedan las aves o huevos debe estar indemne o al menos controlada la enfermedad de Newcastle y la influencia aviar; un certificado extendido y firmado por un veterinario oficial del país tercero exportador, que se ajustará al modelo que apruebe la Comisión Europea; la posible realización de controles "in situ" por expertos veterinarios designados por la Comisión para comprobar el cumplimiento de este reglamento en materia de importación.

c) Intercambios intracomunitarios de animales de la especie bovina y porcina. La necesidad de armonizar el Derecho interno de los países miembros en relación a los intercambios de animales de la especie bovina y porcina, lleva a la UE a dictar una pluralidad de Directivas y sucesivas modificaciones ${ }^{53}$ que han sido paulatinamente incorporadas al Derecho interno.

No obstante, todo el cuerpo normativo comunitario en la materia citada ha sido refundido e incorporado al Derecho nacional en virtud del Reglamento de 13 de octubre de $2000^{54}$.

En dicho Reglamento se recogen las condiciones que debe reunir el

${ }^{52}$ Esta autorización es independiente de la autorización que requieren las explotaciones avícolas para poder iniciar su actividad, y a la que se refiere el artículo 3 del Real Decreto No 328/03, de 14 de marzo, por el que se establece y regula el Plan Sanitario Avícola.

${ }^{53}$ Entre las mismas se sitúa la Directiva No 64/432/CEE, del Consejo, de 26 de junio relativa a los problemas de policía sanitaria de intercambios intracomunitarios de animales de las especies bovina y porcina, la cual fue modificada y actualizada por la Directiva No 97/12/CE, del Consejo de 17 de marzo. A su vez, esta última Directiva ha sido modificada por la Directiva No 98/46/CE, del Consejo de 24 de junio y por la Directiva No 98/99/CE, del Consejo de 14 de diciembre, y más recientemente por las Directivas No 2000/15/CE, del Parlamento Europeo y del Consejo, de 10 de abril y por la No 2000/20/CE, del Parlamento Europeo y del Consejo de 16 de mayo.

${ }^{54}$ Real Decreto No $1716 / 00$, de 13 de octubre. 
ganado bovino y porcino para poder circular en los intercambios intracomunitarios, entre las que destacan: el contar con un certificado sanitario de origen que deberá conservarse hasta el lugar de destino, el estar debidamente identificados, el ser sometidos a un control por parte de un veterinario oficial dentro de las 24 horas previas a su salida y no mostrar signos clínicos de enfermedad. Se establecen requisitos adicionales para los intercambios de animales de la especie bovina y porcina de reproducción o producción.

Para los intercambios de animales de las especies bovina y porcina se establecen las condiciones para su comercio, entre las que se encuentran las relativas a su transporte ${ }^{55}$; el régimen de los comerciantes u operadores comerciales $^{56}$; los requisitos que deben reunir los centros de concentración de animales exclusivos para el intercambio intracomunitario ${ }^{57}$.

3. Controles veterinarios aplicables a productos procedentes de terceros países y a los animales y sus productos en los intercambios intracomunitarios.

a) Productos procedentes de países terceros. Sendas Directivas del Consejo de 18 de diciembre de 1997, regulan los referidos controles veterinarios $^{58}$, y armonizan las medidas necesarias para garantizar la protección de la salud de las personas ${ }^{59}$ y de los animales, evitando la propagación de enfermedades en la UE, garantizando, a su vez, la seguridad del abastecimiento y estabilización de los mercados.

Dicha normativa comunitaria ha sido incorporada al Derecho español a través del Reglamento de 23 de diciembre de $1999^{60}$.

${ }^{55}$ Medios de transporte que garanticen la protección de los animales, obligación de desinfección de los vehículos, etc. (artículo 14 del Real Decreto No 1716/00).

${ }^{56}$ Obligación de estar inscritos y autorizados por la CC.AA., contar con instalaciones autorizadas por la CC. AA, tener a los animales identificados y con documentación sanitaria, contar con un Libro de Registro de la explotación (artículo 16 del Real Decreto No 1716/00).

${ }^{57} \mathrm{~V}$. gr, necesidad de autorización otorgada por la CC.AA. donde radiquen (artículo 19 y 20 del Real Decreto No 1716/00).

${ }^{58}$ Directiva No 97/78/CE, del Consejo, de 18 de diciembre, por la que debe aplicarse un régimen de control único para los productos de origen animal procedentes de terceros países, y su complementaria, la Directiva No 97/79/CE, del Consejo, de 18 de diciembre, que se refiere a la organización de los controles veterinarios de los productos que se introducen en la Comunidad procedentes de terceros países.

${ }^{59}$ Larrañaga Coll, I. J., y otros, Control e higiene de los alimentos (Madrid, MacGraw Hill, 1998).

${ }^{60}$ Madrid, No 1977/99, de 23 de diciembre, que establece los principios relativos a la organización de los controles veterinarios sobre productos procedentes de países terceros, modificado por el Real Decreto No 731/07, de 8 de junio; y desarrollado 
Entre las peculiaridades aplicables a la importación de productos procedentes de países terceros, que no se aplica en los intercambios intracomunitarios, destaca la obligación de su introducción en el territorio de la UE a través de un Puesto de Inspección Fronterizo [= PIF] autorizado, en el cual serán sometidos a los controles veterinarios efectuados por el personal situado bajo la responsabilidad del veterinario oficial, el cual una vez realizados los mismos expedirá un certificado para la partida de productos de que se trate, indicando el estado de dichos controles ${ }^{61}$.

Además, prevé la adopción de medidas de salvaguardia cuando en el territorio de un país tercero se declare o propague una de las enfermedades animales de declaración obligatoria ${ }^{62}$ o cualquier otro fenómeno o causa que pueda constituir grave peligro para la salud pública o la sanidad animal o cuando cualquier otra razón grave de protección de la salud humana o de policía sanitaria lo justifique. Entre dichas medidas de salvaguardia se sitúan: la posibilidad de suspender las importaciones procedentes de dicho país tercero; la fijación de condiciones especiales para los productos procedentes del país tercero; el establecimiento de requisitos de control adecuados.

Si de dichos controles resultase que alguna partida de productos puede constituir un peligro para la salud humana o la sanidad animal, la autoridad veterinaria competente podrá intervenir y rechazar con destrucción la correspondiente partida, e informar de ello a la Comisión Europea y a los demás PIF.

b) Animales y sus productos en los intercambios intracomunitarios. Los controles veterinarios y zootécnicos aplicables en los intercambios intracomunitarios de determinados animales vivos y sus productos ( v.gr. esperma, óvulos, huevos, carnes frescas, productos cárnicos destinados al consumo humano, leche tratada térmicamente, carnes picadas, preparados de carne, etc) se regulan por los Reglamentos de 15

por la Orden PRE/2042/, de 2007, de 4 de julio, que modifica el Anexo I del Real Decreto No 1977/99. A efectos de este Reglamento se entiende por productos las carnes frescas, carne picada y preparados de carne, carnes frescas de aves de corral, carne de conejo y carne de caza de granja, carne de caza silvestre, todos los productos o subproductos de origen animal, moluscos bivalvos vivos, leche y derivados, animales muertos y desperdicios de origen animal, esperma y embriones de bovino, porcino, y de otras especies animales, etc. (Anexo II, del Real Decreto No 1977/99, de 23 de diciembre)

${ }^{61}$ En el mismo sentido se han recogido las inspecciones en frontera de animales o productos procedentes de terceros países en la LSA. (artículo12).

${ }^{62}$ A las mismas se refiere el Real Decreto No 617/2007, de 16 de mayo, por el que se establece la lista de las enfermedades de los animales de declaración obligatoria y se regula su notificación. 
de enero de 1993 y de 30 de octubre de $1992^{63}$; y por lo que respecta a productos de origen animal no sometidos a dichos reglamentos, por el Reglamento de 29 de diciembre de $1994^{64}$.

La supresión de los controles veterinarios en frontera, dentro del territorio de la UE obliga a establecer controles en origen y en destino. En este sentido, el Reglamento de 30 de octubre de 1992 regula los controles en origen $^{65}$, entre los que destacan la necesidad de que los animales y productos estén identificados de conformidad con la normativa comunitaria, estén registrados, a fin de poder identificar la explotación de origen, y la necesidad de que vayan acompañados durante el transporte de los certificados sanitarios y de cualesquiera otros documentos previstos en las disposiciones estatales y comunitarias relativas a cada especie animal y sus productos. Estos certificados o documentos serán expedidos por el veterinario oficial responsable de la explotación o centro de origen.

Los controles en destino se realizarán por los veterinarios oficiales de las CC. AA. ${ }^{66}$.

También en el supuesto de intercambios intracomunitarios se prevé la posibilidad de adoptar medidas de salvaguardia, como la puesta en cuarentena de los animales o la adopción de medidas cautelares, cuando como consecuencia de los controles en destino se compruebe la existencia de una epizootia o zoonosis que pueda suponer un peligro grave para la salud pública o la sanidad animal. Los órganos de las CC. AA. comunicarán las medidas adoptadas al Ministerio competente en materia de Agricultura y, en su caso, al Ministerio de Sanidad y Política Social si se trata de una zoonosis o enfermedad que pueda suponer un peligro grave para la salud pública; a su vez, dichos Departamentos Ministeriales deberán comunicar las medidas adoptadas a la Comisión Europea y demás Estados miembros.

Por su parte, el Reglamento de 15 de enero de 1993 establece que los controles veterinarios sobre los productos de origen animal que se destinen a intercambios intracomunitarios, no se realizarán en las fronteras,

${ }^{63}$ Real Decreto No 49/93, de 15 de enero, relativo a los controles veterinarios aplicables en los intercambios intracomunitarios de los productos de origen animal, desarrollado por la Orden PRE 1764/2006, de 5 de junio; y Real Decreto No $1316 / 92$, de 30 de octubre, por el que se establecen los controles veterinarios y zootécnicos aplicables a los intercambios intracomunitarios de determinados animales vivos y productos con vistas a la realización del mercado interior. Este último Reglamento ha sido modificado por el Real Decreto No 500/03, de 2 de mayo.

${ }^{64}$ Real Decreto No 2551/94, de 29 de diciembre, modificado por el Real Decreto No 74/98, de 23 de enero y por el Real Decreto No 500/03, de 2 de mayo.

${ }^{65}$ Artículos 3 y 4 del Real Decreto No 1316/92, de 30 de octubre.

${ }^{66}$ Artículos 5 a 9 del Real Decreto No 1316/92, de 30 de octubre. 
sino en origen, durante el transporte y en destino, debiendo aplicar el principio de confianza mutua en los controles efectuados por el Estado de expedición.

Así, por lo que respecta a los controles en origen, los productos deben ir acompañados de un certificado de inspección veterinaria y de un certificado de salubridad; el cumplimiento de dichas exigencias serán verificadas en el lugar de destino por las autoridades competentes. Si en dicho control de destino se comprueba la existencia de alguna enfermedad o zoonosis que pueda constituir un peligro grave para los animales o para el hombre, o que los productos proceden de una región afectada por una enfermedad epizoótica, se ordenará la destrucción del lote.

Tanto el Reglamento de 30 de octubre de 1992 como el de 15 de enero de 1993 recogen la responsabilidad de garantizar que los controles veterinarios $\mathrm{y}$, cuando proceda, la certificación, se efectúan de forma adecuada $^{67}$.

Por lo que respecta a las condiciones de sanidad animal aplicables a los intercambios e importaciones de productos de origen animal ${ }^{68}$ no sometidos al Reglamento de 15 de enero de 1993 ni al Reglamento de 30 de octubre de 1992, el Reglamento de 29 de diciembre de $1994^{69}$ establece unas condiciones que no difieren sustancialmente de las analizadas a grandes rasgos en dichos Reglamentos.

\section{LA PROTECCIÓN DE LOS ANIMALES DURANTE EL TRANSPORTE}

Las acciones de la Unión Europea relativas al bienestar de los animales se encuentran íntimamente relacionadas con la política comunitaria sobre sanidad animal. No cabe duda que el bienestar animal va a redundar en una mejora de la sanidad pecuaria y por derivación, cuando nos referimos a animales de producción, en una garantía de seguridad alimentaria ${ }^{70}$.

${ }^{67} \mathrm{Al}$ respecto, la Directiva No 96/93/CE, del Consejo de 17 de diciembre, relativa a la certificación de animales y productos animales y el Real Decreto No 556/98, de 2 de abril, por el que se establecen las normas para expedir la certificación de animales y productos animales exigida por la normativa veterinaria; modificado por el Real Decreto No 2297/2004, de 10 de diciembre.

${ }^{68}$ Leche y productos a base de la misma para usos distintos del consumo humano, tripas de animales, pieles de ungulados, huesos, cuernos, pezuñas, proteínas animales elaboradas, sangre, sueros procedentes de los equinos, etc.

${ }^{69}$ Real Decreto No 2551/94, de 29 de diciembre, modificado por el Real Decreto No 74/98, de 23 de enero y por el Real Decreto No 500/03, de 2 de mayo.

${ }^{70}$ Véanse: Pérez Monguió, José Ma., Animales de compañía (Barcelona, Bosch, 2005), pp.11 ss.; Carpenter, E., Animals and Ethics (London, Watkinns, 1980); Aparicio, M. A. - Vargas, Juan de Dios - Prieto, L., Consideraciones sobre el bienes- 
La normativa europea sobre protección y bienestar animal es muy variada. En el seno del Consejo de Europa se han aprobado diversos Convenios sobre bienestar animal ${ }^{71}$ que están sirviendo de base a las instituciones de la Unión Europea para elaborar la normativa en esta materia.

El Tratado de la Unión Europea, en la reforma llevada a cabo por el “Tratado de Ámsterdam”, vino a consagrar la necesidad de tener en cuenta el bienestar animal en todas las políticas comunitarias que puedan tener relación con la materia.

Así, el citado tratado introduce como anexo el Protocolo sobre la protección y el bienestar de los animales, en el que se reconoce la necesidad de proteger a los animales como seres sensibles ${ }^{72}$.

Junto al Derecho originario nos encontramos numerosos Reglamentos, directivas y Decisiones que se centran en la protección animal en el momento de la producción o cría, del transporte y del sacrificio. Podemos decir que el bienestar animal debe producirse durante toda la vida del animal y en su sacrificio. A ello hemos de unir específicas normas para la protección de determinadas especies animales (los pollos destinados a la producción de carne, las gallinas ponedoras, los terneros, los cerdos o los animales salvajes que viven en un entorno zoológico $)^{73}$.

tar animal, en www.sian.info.ve/porcinos/publicaciones/encuentros/viii_encuentro/ memorias; BANDO CASADO, H. C., La protección de la salud alimentaria, en Estudios sobre consumo, 20 (1991); LOSADA MANOSALVAS, I., La gestión de la seguridad alimentaria (Barcelona, Ariel, 2001); Mellado Ruiz, L., Desarrollo y ejecución de las competencias sobre seguridad alimentaria por la Comunidad Autónoma de Andalucía, en Revista Andaluza de Administración Pública, 2 (2003); Muñíz EspadA, E., Las nuevas orientaciones en materia de seguridad alimentaria, en Noticias de la Unión Europea, 213 (2002).

${ }^{71}$ Convenio para la Protección de los animales en el transporte internacional (París, 13 de diciembre de 1968); Convenio para la protección de los animales en explotaciones ganaderas (Estrasburgo, 10 de marzo de 1976); Convenio para la protección de los animales al sacrificio (Estrasburgo, 10 de mayo de 1979); Convenio para la protección de los animales de compañia (Estrasburgo, octubre de 1987); Convenio para la protección de los animales de experimentación (Estrasburgo, 18 de marzo de 1986). Todos estos convenios y demás normativa sobre bienestar animal puede consultarse en: https:// www.mapa.es/es/ganaderia/pags/bienestar/pr_granja.htm

${ }^{72} \mathrm{Al}$ respecto, Gaspar, Zur Stellung des Tieres im Gemeinschaftrecht (Baden-Baden, Nomos, 2001); Doménech Pascual, G., Bienestar animal contra derechos fundamentales (Barcelona, Atelier, 2004).

${ }^{73}$ Entre la normativa de Derecho derivado podemos citar: Reglamento (CE) No $1 / 2005$, del Consejo de 22 de diciembre de 2004, relativo a la protección de los animales durante el transporte y las operaciones conexas; Directiva No 98/58/CE de 20 de julio de 1998, relativa a la protección de los animales en las explotaciones ganaderas; Directiva No 93/119/CE del Consejo, de 23 de diciembre de 1993, relativa a 
Recientemente la Unión Europea ha aprobado el "Plan de Acción para el bienestar de los animales 2006-2010"74, que recoge medidas destinadas a asegurar la protección y el bienestar de los animales en la UE y a nivel internacional.

Entre sus objetivos destaca la clarificación de la normativa comunitaria en la materia y la realización de propuestas en los aspectos en los que presente carencias.

Uno de los aspectos de la vida animal sujetos a protección hace referencia a las condiciones en que deben viajar los animales. En este sentido, el Reglamento comunitario de 22 de diciembre de $2005^{75}$, de protección de los animales durante el transporte intensifica los controles anteriormente previstos para evitar el dolor y el sufrimiento y proteger el bienestar y la salud de los animales durante y después del transporte. Para ello se establecen obligaciones documentales y de planificación del viaje para los transportistas; se detallan los deberes y obligaciones de las autoridades competentes en relación a la autorización de transportistas, la autorización de viajes largos y la inspección de las hojas de ruta; se presta especial atención a la necesidad de que el personal que interviene en el transporte de animales esté debidamente formado; y se establece el régimen sancionador en la materia.

Así, para itinerarios superiores a $85 \mathrm{~km}$ los transportistas deberán disponer de una autorización otorgada por la autoridad competente, para lo cual deberán disponer de equipos y personal adecuado a tal fin. Si el viaje es superior a 8 horas, el solicitante de la autorización debe presentar documentos que acrediten la competencia de los conductores y acompañantes y certificados de aprobación de los medios de transporte que utilice y de que emplea un sistema de navegación por satélite en el vehículo.

La autorización tiene una validez de 5 años y un formato europeo armonizado. Además, los transportistas en los viajes largos a través de varios Estados deberán llevar un cuaderno de a bordo donde se incluirá la información sobre el viaje.

la protección de los animales en el momento de su sacrificio o matanza; Directiva No 2007/43/CE, del Consejo, por la que se establecen las disposiciones mínimas para la protección de pollos destinados a la producción de carne, etc.

${ }^{74}$ Comunicación de la Comisión al Parlamento Europeo y al Consejo de 23 de enero de 2006 relativa a un "Plan de Acción Comunitario sobre Protección y Bienestar de los Animales" 2006-2010( DOC 49 de 28 de febrero de 2006).

${ }^{75}$ Reglamento (CE) No 1/2005 del Consejo, de 22 de diciembre de 2004, relativo a la protección de los animales durante el transporte y las operaciones conexas y por el que se modifican varias Directivas. 
Toda la documentación señalada debe ser controlada por la autoridad competente.

El Reglamento comunitario introduce una pormenorizada regulación de las normas técnicas aplicables en trayectos de duración superior a 8 horas tanto a los vehículos (regulación de la temperatura, suministro de agua permanente, mejora en el transporte a bordo de buques, etc.), como a los animales (prohibición de transporte de animales jóvenes, de hembras preñadas en la última etapa de la gestación y durante la semana posterior al parto...). Igualmente, se prevén limitaciones a la duración del transporte según la especie animal.

El bienestar de los animales durante el transporte se complementa con la regulación de los controles en los "puntos de parada", o sea, en los lugares en los que los animales deben ser descargados cuando sean objeto de viajes de largo recorrido. Así, el Reglamento comunitario de 25 de junio de 1997 sobre criterios comunitarios de los puntos de parada ${ }^{76}$, establece que estos puntos deberán utilizarse para acoger, alimentar, dar de beber, descansar... los animales. Cada Estado miembro determinará los puntos de parada, ahora llamados "puntos de control" que podrán limitarse a determinada categoría de animales o a determinadas situaciones sanitarias, y se notificará a la Comisión que establecerá la lista de los puntos de control. Para la autorización de los puntos de control, los mismos deben cumplir una serie de condiciones relativas a las instalaciones y al personal y equipos que estén en contacto con los animales, contar con un veterinario oficial y someterse a inspecciones periódicas.

De no respetarse la legislación comunitaria la Comisión podrá suspender la utilización de un "puesto de control" o retirarlo de la lista.

En España se han recogido algunas determinaciones de carácter básico en cuanto al cuidado de los animales durante el transporte en la Ley de 7 de noviembre de 2007, para el Cuidado de los animales, en su explotación, transporte, experimentación y sacrificio. El artículo 5 de esta Ley se refiere al transporte de animales fijándose como objetivo que a los animales no se les causen lesiones o sufrimientos innecesarios. Para ello impone a las Administraciones públicas la obligación de adoptar las medidas necesarias; destaca el papel que los medios de transporte y las instalaciones de carga y descarga juegan en la consecución de aquel objetivo; y, presta especial atención a la adecuada formación que debe tener el personal que manipule los animales.

${ }^{76}$ Reglamento (CE) No 1255/97, del Consejo, de 25 de junio de 1997, sobre los criterios comunitarios que deben cumplir los puntos de parada y por el que se adapta el plan de viaje mencionado en el Anexo de la Directiva No 91/628/CEE; modificado por Reglamento (CE) No 1040/2003 del Consejo, de 10 de junio de 2003. 


\section{REFLEXIÓN FINAL}

La intervención administrativa en relación con el movimiento del ganado y sus productos resulta esencial para evitar la propagación de epizootias y zoonosis. En aquella intervención la UE juega un papel destacado. Pero la abundante regulación normativa comunitaria, la ausencia de unas reglas o principios básicos para los intercambios intracomunitarios y con terceros países de animales, y la técnica de transposición interna, mero reflejo de la normativa comunitaria, dificulta el análisis de la misma. Si a ello unimos que en España contamos además con la normativa de la UE y la normativa estatal de transposición, con la normativa aprobada por las CC. AA., se complica no sólo el análisis del régimen jurídico aplicable, sino fundamentalmente, la consecución de la sanidad y protección animal durante el movimiento del ganado.

Así, pues, se echa en falta una refundición normativa en la materia.

Por otro lado, la regulación que realiza la LSA. sobre intercambios con terceros países de animales y sus productos debiera haber ido acompañada de una serie de previsiones de carácter básico, e incluso, de competencia plena, referidas a los intercambios intracomunitarios. Así, debiera haberse recogido la exigencia de los controles en origen y en destino a través de los correspondientes certificados sanitarios, la prohibición de realizar el traslado de animales fuera de zonas que hayan sido declaradas por la Comunidad Europea o por el Estado español como afectadas por una determinada epizootia; así como, la exigencia de autorización para el movimiento de animales dentro de dichas zonas.

Del mismo modo, no se entiende cómo el bienestar animal, materia íntimamente relacionada con la sanidad animal, no es objeto de tratamiento en la Ley de sanidad animal. Partiendo de la regulación contenida en la normativa de la UE se podría haber regulado el importante papel que deben adoptar las Administraciones públicas en la materia, la necesidad de formación del personal que interviene en la manipulación de los animales y en las condiciones del medio de transporte y la reducción del tiempo de viaje como elemento esencial para garantizar la protección del animal.

En definitiva, el movimiento y transporte de animales, por la directa incidencia que puede tener en la transmisión de epizootias y zoonosis exige de una regulación normativa unitaria, no sólo a nivel comunitario, sino internacional, por cuanto que la sanidad animal y la protección de la salud humana no conocen de fronteras. Dicha regulación debe partir de la formulación de unos principios y normas básicas sanitarias aplicables a los intercambios de animales y sus productos.

[Recibido el 12 de marzo y aprobado el 26 de abril de 2010]. 


\section{BiBLIOGRAFÍA}

Adrián Arnaiz, A. J, Globalización y seguridad alimentaria en la Unión Europea, en Revista de Estudios Europeos, 25 (2000).

Aparicio, M. A. - Vargas, Juan de Dios - Prieto, L., Consideraciones sobre el Bienestar Animal, en: www. sian.info.ve/porcinos/publicaciones/encuentros/viii_encuentro/ memorias

Argullol Murgadas, E., Competencias de la Comunidad Europea y de las CC. AA. en materia de política agraria, en La integración de España en las Comunidades Europeas y las competencias de las CC. AA. (Barcelona, Generalitat de Cataluña, 1985).

Buxade Carbo, C., El desafio: ganadería española. CEE de los Doce (Madrid, Ediciones Mundi Prensa, 1988).

Callejo, Javier, La crisis de la Encefalopatía Espongiforme: Huecos en el modelo social de consumo, en Revista de Estudios sobre Consumo, 58 (2001).

Carpenter, E., Animals and ethics (London, Watkinns, 1980).

Cartagena Pastor, F., Protección alimentaria del consumidor. Aspectos legales y aplicaciones prácticas de investigación y enjuiciamiento de los delitos contra la salud pública derivados del tratamiento ilegal de animales destinados al consumo humano. Consideraciones generales, en Revista de Estudios sobre Consumo, 58 (2001).

Castillo Gamero, N. - Hernández la Fuente, A., La política agraria, en Tratado de Derecho Comunitario Europeo (Madrid, civitas, 1986), III.

Doménech Pascual, G., Bienestar animal contra derechos fundamentales (Barcelona, Atelier, 2004).

GASPAR, Zur Stellung des Tieres im Gemeinschaftrecht (Baden-Baden, Nomos, 2001).

GonZÁlez Botija, F., La crisis de las vacas locas y los límites de las protecciones de la salud pública en el mercado interior, en Revista de Estudios Europeos, 17 (1997).

GonZÁlez Ríos, Isabel, Las explotaciones ganaderas ante la Sanidad Animal. Controles sanitarios, derechos y deberes de los titulares de las mismas, en Revista de Justicia Administrativa, 41 (2008).

GonzÁlez Ríos, Isabel, Sanidad animal y seguridad alimentaria en los productos de origen animal (Granada, Comares, 2004).

Larrañaga Coll, I. J., y otros, Control e higiene de los alimentos (Madrid, MacGraw Hill., 1998).

Losada Manosalvas, I., La gestión de la seguridad alimentaria (Barcelona, Ariel, 2001).

Martín González, Salud pública. Concepto y encuadramiento (Madrid, 1970), III.

Martín Mateo, Ramón, Ordenación pública del sector salud, en Revista de Administración Pública, 84 (1997).

Mellado Ruiz, L., Desarrollo y ejecución de las competencias sobre seguridad alimentaria por la Comunidad Autónoma de Andalucía, en Revista Andaluza de Administración Pública, 2 (2003).

Muñíz Espada, E., Las nuevas orientaciones en materia de seguridad alimentaria, en Noticias de la Unión Europea, 213 (2002).

Muñoz Machado, Santiago, Los animales y el Derecho (Madrid, Civitas, 1999).

Navarro Caro, J., Cuestiones de constitucionalidad relativas al reparto competencial entre el Estado y las Comunidades Autónomas en Derecho Agrario Español, en Derecho Agrario Español y de todas las Comunidades Autónomas (Zaragoza, Diputación Provincial de Aragón, 1993). 
Pérez Monguió, José Ma., Animales de compañia (Barcelona, Bosch, 2005).

Quintana López, Tomás, Derecho Veterinario: epizootias y sanidad animal (Madrid, Marcial Pons, 1993).

Rebollo Puig, Manuel, Potestad sancionadora, alimentación y salud pública (Madrid, Ministerio de Administraciones Públicas, 1989).

SÁnchez Blanco, Ángel, El consumidor ante la política de abastecimiento y ante la política comercial, en Revista de Administración Pública, 85 (1978).

SÁnCHEZ Blanco, Ángel, El consumidor ante la política de abastecimiento y ante la politica comercial, en Revista de Administración Pública, 85 (1978).

VAlENZUEla GaRCía, F., La intervención administrativa en materia de alimentación, en Documentación Administrativa, 194 (1982).

Valenzuela García, F., La intervención administrativa en materia de alimentación, en Documentación Administrativa, 194 (1982).

Yuste Grijalva, J. F., Salud pública y desarrollo, en Documentación Administrativa, 114 (1967). 